Tropical Journal of Pharmaceutical Research November 2016; 15 (11): 2407-2413

ISSN: $1596-5996$ (print); 1596-9827 (electronic)

(C) Pharmacotherapy Group, Faculty of Pharmacy, University of Benin, Benin City, 300001 Nigeria.

All rights reserved.

Available online at http://www.tjpr.org

Original Research Article

http://dx.doi.org/10.4314/tjpr.v15i11.15

\title{
Determination of effect of aspirin and captopril on cat glomerular filtration rate using renovascular hypertension scintigraphy
}

\author{
Esmaeil Gharepapagh ${ }^{1}$, Gholamreza Assadnassab ${ }^{2 *}$ and Solmaz Rahmani \\ Barouji \\ ${ }^{1}$ Department of Radiology, Division of Nuclear Medicine, Tabriz University of Medical Sciences, ${ }^{2}$ Department of Clinical \\ Science, Tabriz Branch, Islamic Azad University, Tabriz, Iran, ${ }^{3}$ School of Traditional Medicine, Tabriz University of Medical \\ Science, Tabriz, Iran
}

${ }^{*}$ For correspondence: Email: assadnassabgh@iaut.ac.ir; Tel: 989144121145

Received: 11 May 2016

Revised accepted: 12 October 2016

\begin{abstract}
Purpose: To compare the effects of aspirin and captopril on glomerular filtration rate (GFR) during renal perfusion scintigraphy in cats after experimentally-induced unilateral renal-artery stenosis.

Methods: Twenty mixed-breed adult cats weighing 3-4 $\mathrm{kg}$ were used. After conducting renal scintigraphy operations, their GFRs were measured by the method of Gate. Four days later, renovascular hypertension was induced through renal-artery stenosis by clipping half of the left renalarteries. Renal scintigraphy was conducted after four days. After confirming the presence of hypertension, the cats were divided into two groups of 10 animals each (aspirin and captopril groups, respectively). The drugs were administered orally to the groups. One hour later, scintigraphic operations were repeated under anaesthesia after injecting $2 \mathrm{mCi}$ of the radiopharmaceutical, technetium-99m diethylene triamine pentaacetic acid (99mTc-DTPA), via the femoral vein as a bolus dose. In all groups, regions of interest (ROIs) were drawn and GFRs were measured by Gate method.

Results: Mean total GFR (both right and left kidneys) in operated animals treated with captopril was $5.459 \mathrm{ml} / \mathrm{min}$ while the mean value for the left kidney and right kidneys were 1.585 and $3.874 \mathrm{ml} / \mathrm{min}$, respectively. In operated animals treated with aspirin, mean total GFR was $5.440 \mathrm{ml} / \mathrm{min}$, while the values for the left kidney and right kidneys were 1.567 and $3.866 \mathrm{ml} / \mathrm{min}$, respectively.

Conclusion: These results indicate that aspirin has similar reduction effect on GFRs and similar shape of renograms as captopril in cat renovascular hypertension scintigraphy. Thus, aspirin is a suitable substitute for captopril in the diagnosis of renovascular hypertension in renal scintigraphy.
\end{abstract}

Keywords: Aspirin, Captopril, Cat, Renovascular Hypertension, Scintigraphy

Tropical Journal of Pharmaceutical Research is indexed by Science Citation Index (SciSearch), Scopus, International Pharmaceutical Abstract, Chemical Abstracts, Embase, Index Copernicus, EBSCO, African Index Medicus, JournalSeek, Journal Citation Reports/Science Edition, Directory of Open Access Journals (DOAJ), African Journal Online, Bioline International, Open-J-Gate and Pharmacy Abstracts

\section{INTRODUCTION}

Scintigraphy has been proposed as a practical method in nuclear medicine. In addition, it is one of the diagnostic imaging techniques in renal studies and renal diseases [1]. Nowadays, renal artery stenosis is considered as one of the chief causes of kidney failure. The most common cause of renal vascular disease is atherosclerotic stenosis. In addition, ischemic nephropathy as a chronic renal damage is caused by hemodynamically severe renal artery stenosis. Nuclear renography is performed after prescription dose of angiotensin convertingenzyme inhibitor drug, and observation of significant decrease in renal blood flow is 
considered an excellent diagnostic screening method for evaluation of renal artery stenosis $[2,3]$. In this method, a basic renogram is performed using technetium-99m diethylenetriamine pentaacetic acid ( ${ }^{99 m}$ Tc-DTPA). After two days at least, a special dose of captopril is administered orally and then renography must be repeated. Captopril inhibits the effect of angiotensin-converting enzyme and decreases the level of angiotensin II in the blood. Furthermore, it inhibits efferent arteriole constriction which plays a vital role in maintaining glomerular filtration in patients with renal artery disease. There is a crucial change in captopril renogram of patients with renovascular hypertension due to the profound effect of captopril on decreasing glomerular filtration rate (GFR) on the affected right or left kidney. This change is measured by a decrease in the uptake of administered radionuclide in the abnormal kidney. Furthermore, radioactivity clearance rate is significantly decreased in the damaged kidney. No change is observed in renogram after administration of captopril in patients whose hypertension is not caused by renal vascular disease $[1,3,4]$.There are several techniques used for measuring GFR [2,3]. Total (both right and left kidney) GFR or differential (left or right kidney) GFR can be estimated by the Gate's formula after using ${ }^{99 \mathrm{~m}}$ Tc-DTPA radiotracer in nuclear medicine. Being simple, this scintigraphy method just needs short imaging scans in order to determine the GFR directly through passing and updating ${ }^{99 m}$ Tc-DTPA by the kidney. Normal kidney renography curve differs significantly from that of abnormal kidney $[1,3]$.

A decrease in GFR (measured with ${ }^{99 m}$ Tc-DTPA radiotracer) up to $10 \%$ or more indicates high possibility of renovascular hypertension, while a decrease to 5-9\% indicates average possibility $[3,5]$. A delay in the peak time $\left(T_{\max }\right)$ or an increase in clearance time of the radiopharmaceutical is one of the criteria for positive scan. The sensitivity and specificity of scintigraphy scans in diagnosis of renovascular hypertension have been generally reported in various studies as ranging between $83 \%-100$ and $62 \%-100$, respectively [3].

This study was aimed at comparing the effect of aspirin and captopril on GFR in renal perfusion scintigraphy in the cat after experimentally induced unilateral renal-artery stenosis.

\section{EXPERIMENTAL}

\section{Materials}

In this study, Siemens gammascan camera (MIE
Inc., Germany) and Capintec CRC-5 dose calibrator machine (Capintec Inc., USA) were used. Diethylene triamine pentaacetate (DTPA) kit (Pars Isotope Company, Iran) was applied. Molybdenum-technetium generator and DTPAKit were confirmed by the Atomic Energy Organization of Iran.

\section{Animals}

Twenty local mixed breed healthy adult cats weighing $3.5 \pm 0.5 \mathrm{~kg}$ were selected at random for this study. The animals were kept in separate cages at an ambient temperature of $22 \pm 4{ }^{\circ} \mathrm{C}$ with free access to water and feed. Necessary blood parasitological tests and clinical examination were performed. After confirming their good health, ivermectin (Razak, Iran), antiparasite drug, was administered by subcutaneous injection at a dose of $0.2 \mathrm{mg} / \mathrm{kg}$ body weight [6].

This study was conducted with the collaborations of Tabriz University of Medical Sciences and Tabriz Branch Islamic Azad University in 2015. Procedures were carried out under the ethical guideline of Faculty of Veterinary Medicine, Tabriz Branch, Islamic Azad University (No.13/11/5/11025) for the care and use of laboratory animals (National Institutes of Health Publication No. 85-23, 1985) [7].

\section{Methods}

Technetium-99m was milked from molybdenumtechnetium generator and then it was added to DTPA kit. ${ }^{99 m}$ Tc-DTPA radiotracer was made according to kit manufacturer's instructions.

The animals were anesthetized with ketamine (Alfasan, Woerden, Holland) $10 \mathrm{mg} / \mathrm{kg}$ as the main drug and acepromazine (Alfasan, Woerden, Holland) $0.05 \mathrm{mg} / \mathrm{kg}$ as the pre-anesthetic drug [8]. The anesthetized animal was positioned on its back with stretched legs and arms, and radiopharmaceutical ${ }^{99 m}$ Tc-DTPA was injected via the femoral vein as a bolus at a dose of 2 $\mathrm{mCi}$. Immediately after intravenous injection of radioactive agent, scintigraphy was performed using the standard method by setting the scintillator of the machine under the table near the kidneys. During the operation, the animal was kept steady to minimize movements, in order to make sure that the scanning process was not disrupted. The most appropriate injection is the one with proper radioactivity in low bolus volume. For better imaging, the animal's injection area was covered with a lead shield. The computer program was set until images were scanned in subsequent times [9]. Secondary 
activity of the syringe after injection was measured by the same dose calibrating machine to ensure the administration of radiotracer inside the body.

In the renal scintigraphy scans obtained, the absorbed dose of radioactive radionuclide was evaluated by computer drawing based on the specified ranges using region of interested (ROI) method in the hot spot areas of the kidneys. Then in the drawn ROls, radioactive counts in each kidney region together with their background region were determined. Afterwards, GFRs were measured by using commercial software based on Gate's formula [1,3].

After primary scans, which are considered as the necessary and comparative images for the evaluation of other scans, the animals were kept with care in separate cages. After four days (for clearance of used radioactive agents from the animals), they were prepared for the common standard operations.

Renal artery stenosis and follow-up renovascular hypertensions were induced in all the animals by the common standard surgeries. After surgical opening of the abdomen, first, diameter of the left renal artery was measured using a sterilized caliper. Thereafter, almost half of left renal artery was clipped, and an appropriate stereomicroscope, in compliance with the sterilization condition, was used to find, isolate and work on the renal artery.

After four days, renal scintigraphy was performed on the operated animals. Following confirmation of hypertension caused by unilateral renal-artery stenosis, the animals were assigned into two separate equal groups. Each group consisted of ten cats. After four days (for injection radiotracer to be cleared from body of animals), aspirin (Amin, Iran) and captopril (Exir, Iran) were administered orally to different groups at a single dose of $5 \mathrm{mg} / \mathrm{kg}$ [10]. Then the scintigraphy operations were repeated after one hour, and GFRs were measured using the same technique as before.

Blood pressures were measured before scintigraphic operations in all groups. Scintigraphy scans were analyzed visually and absorbed radioactive counts were measured in different ROI areas. Finally, the scintigraphic images, renograms and GFRs were evaluated for the different groups.

\section{Statistical analysis}

Student's t-test and ANOVA were carried out for data analysis using SPSS, version 17. $P<0.05$ was considered statistically significant.

\section{RESULTS}

Scintigraphic images were scanned as described above, and their renograms drawn in order to measure GFR in both kidneys. Figure 1 shows the uniformity of kidney radiotracer absorption in the healthy animal.

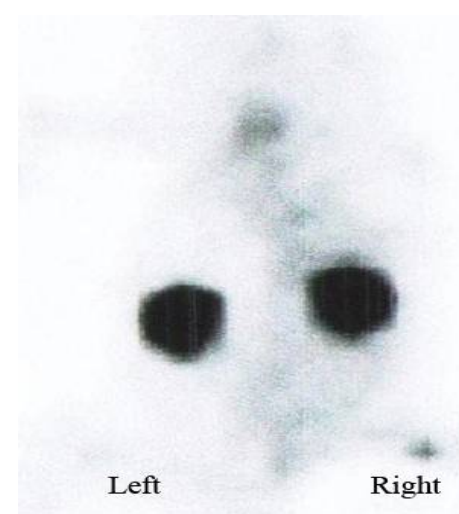

Figure 1: Uniformity of uptake of radioactive agents in a healthy animal

Figure 2 illustrates the distribution of radiotracer in kidneys of an operated animal.

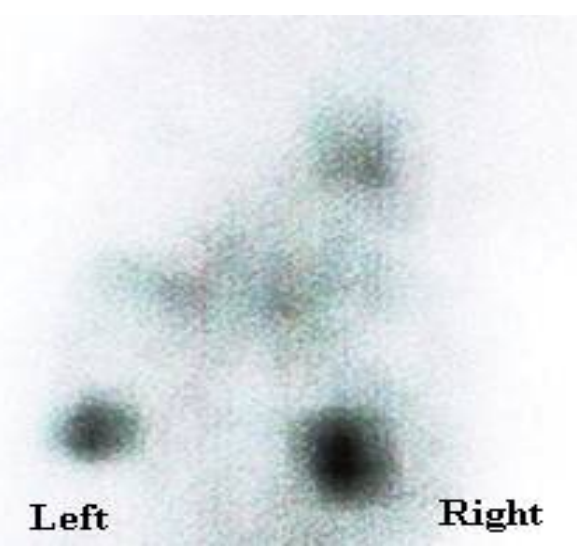

Figure 2: Distribution of radiotracer in kidneys of an operated animal

As shown in Figures 3 and 4, for an operated animal, the ROI areas were specified to investigate the absorption of radiotracer in kidneys and bladder. After exploration of ROI areas, renogram diagram was obtained automatically. Furthermore, in order to improve the quality of scintigraphy scans, a lead shield was used (white area in Figure 3a). This lead shield reduced extra radioactive emissions around kidneys and bladder during the operation. $\mathrm{ROI}$ and renograms for the two different drug groups; aspirin and captopril are shown in 


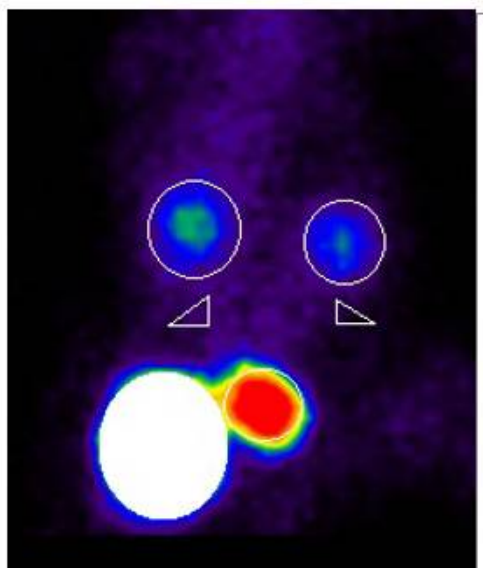

(a)

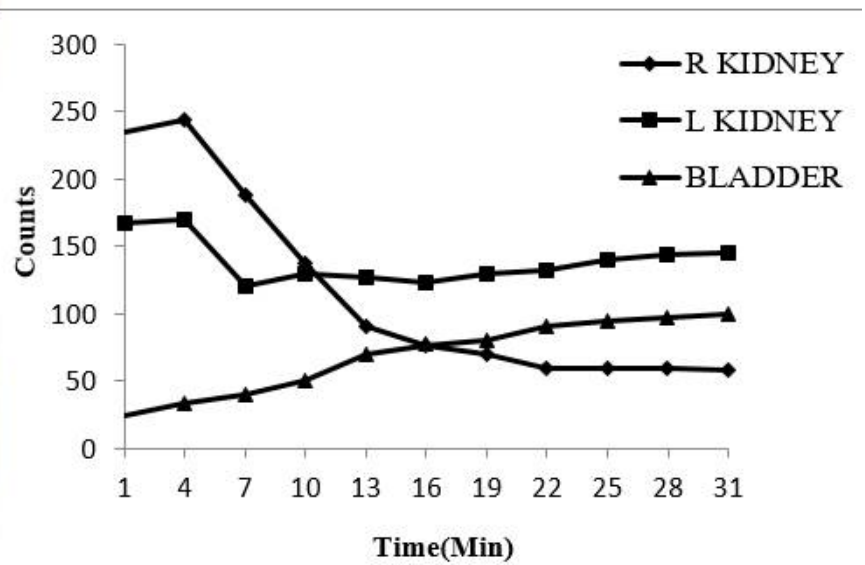

(b)

Figure 3: (a) ROI areas and (b) renogram diagram in an operated animal treated with aspirin

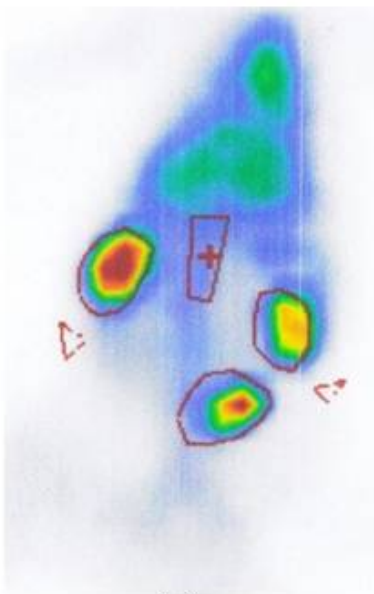

(a)

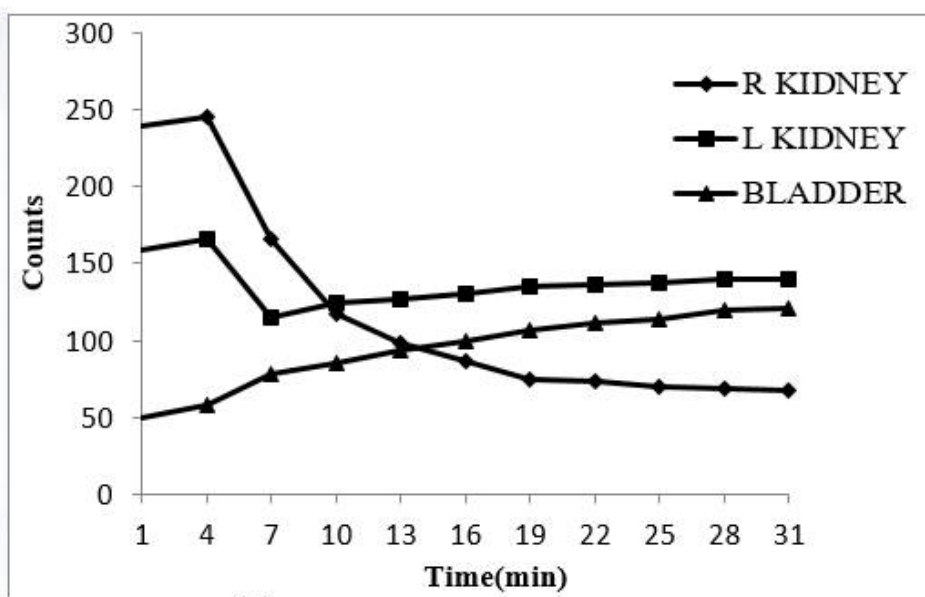

(b)

Figure 4: (a) ROI areas and (b) renogram diagram in an operated animal treated with captopril

Table 1: Statistical description of the GFRs data

\begin{tabular}{lccc}
\hline The Intended side's GFR & $\begin{array}{c}\text { Number of } \\
\text { animals }\end{array}$ & $\begin{array}{c}\text { Mean } \\
\text { (ml/min) }\end{array}$ & $\begin{array}{c}\text { Standard of } \\
\text { deviation }\end{array}$ \\
\hline Total GFR of healthy cats & 20 & 7.861 & 0.168 \\
Left kidney GFR of healthy animals & 20 & 3.984 & 0.085 \\
Right kidney GFR of healthy animals & 20 & 3.883 & 0.120 \\
Total GFR of operated animals & 20 & 5.965 & 0.217 \\
Left kidney GFR in operated animals & 20 & 2.092 & 0.123 \\
Right kidney GFR in operated animals & 20 & 3.876 & 0.122 \\
Total GFR of operated animals treated with captopril & 10 & 5.459 & 0.109 \\
Left kidney GFR in operated animals treated with captopril & 10 & 1.585 & 0.068 \\
Right kidney GFR in operated animals treated with captopril & 10 & 3.874 & 0.082 \\
Total GFR of operated animals treated with aspirin & 10 & 5.440 & 0.065 \\
Left GFR of operated animals in aspirin group & 10 & 1.567 & 0.031 \\
Right GFR of operated animals in aspirin group & 10 & 3.866 & 0.051 \\
\hline
\end{tabular}

Figure 3 and Figure 4, respectively. Table 1 shows the GFR of the cats.

In this study, a significant difference was observed between the means of total GFR in healthy cats $(7.861 \mathrm{ml} / \mathrm{min})$ and the means of total GFR in the cats with stenosis $(5.965 \mathrm{ml} / \mathrm{min})$ in all groups $(p<0.05)$.
A significant difference was observed in all groups between the mean total GFR in healthy cats $(7.861 \mathrm{ml} / \mathrm{min})$ and the mean total GFR in cats with stenosis following treatment with captopril $(5.459 \mathrm{ml} / \mathrm{min})$ and aspirin (5.440 $\mathrm{ml} / \mathrm{min})$ drugs $(p<0.05)$.

Mean of total GFR in operated animals treated with captopril was $5.459 \mathrm{ml} / \mathrm{min}$ and mean of the

Trop J Pharm Res, November 2016; 15(11): 2410 
left kidney and right kidney GFRs were 1.585, $3.874 \mathrm{ml} / \mathrm{min}$ respectively. In operated animals treated with aspirin, mean total GFR was 5.440 $\mathrm{ml} / \mathrm{min}$, while the means of the left kidney GFR and right kidney GFR were 1.567 and 3.866 $\mathrm{ml} / \mathrm{min}$ respectively.

A significant difference was seen in all groups between mean of left GFR in healthy cats (3.984 $\mathrm{ml} / \mathrm{m}$ ) and the left GFR in cats with stenosis $(2.092 \mathrm{ml} / \mathrm{m})$, and also in captopril $(1.585 \mathrm{ml} / \mathrm{m})$ and aspirin $(1.567 \mathrm{ml} / \mathrm{m})$ treatment groups $(p<$ $0.05)$. In all groups, there was no significant difference between right kidney GFR values ( $p>$ 0.05).

However, there was a significant difference between right kidney GFR in healthy animals and left kidney GFR in cats with stenosis. A similar difference was also observed between the right GFR in healthy animals and the left GFR in cats treated with drugs $(p<0.05)$.

\section{DISCUSSION}

The kidneys are among the several different organs which can be evaluated by scintigraphy. Scintigraphic studies of human kidneys have been carried out by using various radiopharmaceuticals. Scintigraphy is used as tool for physiological and anatomical assessments [1-3]. It is also used in animal studies. For instance, this technique has been exploited for studying the kidneys and its diseases in dogs [11] and in cats [12].

Comparison of the scintigraphic images of similar modes in humans and even in healthy animal groups before and after surgery by the uptake of radiopharmaceuticals in both sides of the body can be of medical and diagnostic importance, which is consistent with the reports $[1,3,10]$.

One method for diagnosing renal disease is to determine GFR. In this study, GFR is measured by using some commercial software based on Gate's scintigraphy formula. The results show that, there is a significant difference between GFR value of healthy and operated animals in left kidney $(p<0.05)$.

This study reveals that renal hypertension can be diagnosed by renal scintigraphy which is consistent with reports on studies in this area $[3,5]$. In the present study, renovascular hypertension with experimental renovascular stenosis was diagnosed in the cat. Chen et al evaluated the effects of captopril on ${ }^{99 m}$ Tc-DTPA renography in diagnosis of renal artery stenosis [4]. It was observed that captopril causes GFR reduction by reducing the conversion of angiotensin I to II. This reduction helps to detect renal artery stenosis in renal scintigraphy with high sensitivity. Blaufox et al deployed captopril to detect renovascular hypertension in DTPA scintigraphy. They reported that captopril has a role in GFR reduction as a diagnostic test for evaluating renovascular hypertension in ${ }^{99 \mathrm{~m}} \mathrm{Tc}$ DTPA renal scintigraphy which is released by glomerular filtration [13]. Nally et al studied the shape changes in renograms after captopril administration in patients with renal artery stenosis and proposed captopril renography as a good test for evaluating hypertensive cases. In addition, captopril scintigraphy method was taken into account as a useful non-invasive test for detecting renal artery stenosis [14]. In the present study, captopril showed changes on renovascular hypertension renograms in cats similar to those in humans. This study demonstrates that captopril can be exploited to diagnose renovascular hypertension during renal 99mTc-DTPA scintigraphy, which is consistent with results obtained in human studies $[1,3,14]$.

Dabiri et al compared the effects of aspirin renography in detection of renovascular hypertension with captopril renography. They concluded that ${ }^{99 \mathrm{~m}}$ Tc-DTPA aspirin renography was as sensitive as captopril renography in detection of unilateral renal artery stenosis and could be exploited to diagnose renovascular hypertension during the renal ${ }^{99 m}$ Tc-DTPA scintigraphy [15]. This is in agreement with the results for cat in the present study. The present study revealed that ${ }^{99 \mathrm{~m}} \mathrm{Tc}$ pharmaceutical can be used in cats as well as humans [3] and the other animals $[11,12]$. In addition, renal scintigraphy of cats can be performed easily and their GFR can be measured $[10,16]$. Hecht et al reported renal scintigraphy and determined GFR in cats. Their values of GFR are close to those obtained in this study [16].

The application of these results can help to reduce prevalence and side effects of renovascular hypertension. Furthermore, other appropriate treatment methods can be found with the help of scintigraphy technique through trials with different drugs, and other animal models.

Aspirin works as a prostaglandin synthesis inhibitor and captopril is exploited in detection of human patients with renal hypertension $[17,18]$. Thus aspirin may function as captopril in detection of renal experimental hypertension in animal studies. Seemingly, comparative effects of these drugs in the renogram of felines with renal hypertension for detection of this disease have not been studied simultaneously. 
Stenosis is easily observable by studying scanned images of uptake of radioactive agent and by comparing GFRs. The uptake of radioactive agent by the damaged artery can be measured in comparison with that of healthy kidney. A decrease in the absorption dose count indicates stenosis. Therefore, stenosis and eventually renovascular hypertension can be detected by studying GFRs and scanned images of uptake of radioactive agents.

Currently, captopril renogram scintigraphy is routinely exploited in detecting renovascular hypertension in humans $[1,3]$. Our results show that captopril at $5 \mathrm{mg} / \mathrm{kg}$ can be used to detect unilateral renovascular hypertension in cats.

Comparison of the effects of aspirin scintigraphy with that of captopril in detection of renovascular hypertension in the cat indicates that these scans have similarities with respect to unilateral renal artery stenosis. It also reveals that renograms of aspirin can be used in diagnosis of hypertension caused by renal artery stenosis as a result of inhibition of prostaglandin synthesis, decrease in the release of renin, and reduction of GFR[15,17].

Imanishi et al have found that aspirin renography increased sensitivity from 50 to $93 \%$, but did not change the specificity $(80 \%)$ in the diagnosis of renovascular hypertension and renography [17]. In study by Maini et al, it was found that aspirin renography can be effective just like captopril renography for diagnosis renovascular hypertension [19]. In agreement with previous studies $[18,19]$, we have also found that aspirin can also be used for diagnosis of renovascular hypertension.

\section{CONCLUSION}

The results of the present study indicate that aspirin has similar effects on GFR, scintigraphy scans and renograms as captopril in the detection of renovascular hypertension. On the basis of the results obtained, it is suggested that aspirin renography with ${ }^{99 m}$ Tc-DTPA can be used for the diagnosis of renovascular hypertension. This is particularly so when stenosis of the renal artery cannot be detected by captopril renography.

\section{DECLARATIONS}

\section{Acknowledgement}

The authors would like to thank Tabriz Branch,
Islamic Azad University, Research Department, and Tabesh Nuclear Medicine Center for their assistance.

\section{Conflict of Interest}

No conflict of interest associated with this work.

\section{Contribution of Authors}

The authors declare that this work was done by the authors named in this article and all liabilities pertaining to claims relating to the content of this article will be borne by them.

\section{Open Access}

This is an Open Access article distributed under the terms of the Creative Commons Attribution License, which permits unrestricted use, distribution, and reproduction in any medium, provided the original work is properly credited.

\section{REFERENCES}

1. Mettler FA, Guiberteau MJ, Eds. Essentials of Nuclear Medicine Imaging, 6th edn, Philadelphia: Elsevier Saunders; 2012; pp 316-344.

2. Windus D, Ed. The Washington Manual Nephrology Subspecialty Consult. Washington: Lippincott Williams \& Wilkins; 2008; pp 201-223.

3. Henkin RE, Boles M, Dillehay G, Eds. Nuclear Medicine, 2nd edn., St Louis: Mosby Elsevier; 2006; pp 10541085.

4. Chen $C$, Hoffer P. A simple method of renal scintigraphic analysis with 99m Tc-DTPA and captopril. Radiol1990; 176(2): 365-369.

5. Gambhir SS, Nuclear Medicine in Clinical Diagnosis \& Treatment, 3rd edn, London: Churchill Livingstone; 2004; 1610-1615.

6. Plumb DC, Ed. Plumb's Veterinary Drug Handbook. 4th edn. lowa: lowa State Press; 2005; pp 451-477.

7. Garber JC, Ed. Guide for the care and use of laboratory animals. Washington DC: National Academies Press; 2010; pp 22-61, 193-217.

8. Hall LW, Clarke KW, Trim CM, Eds. Veterinary Anesthesia. 10th edn. London: W.B. Saunders; 1998; pp 463-477.

9. Assadnassab G, Dabiri OS. Application of 99mTc-DTPA Radiotracer in Persian Cat's Renal Scintigraphy. Trop J Pharm Res 2015; 14(9): 1691-1694.

10. Adams HR. Veterinary Pharmacology and Therapeutics, 8th edn. New Jersey: Wiley-Blackwell; 2001; pp 413416, 445-475.

11. Hecht S, Daniel GB, Mitchell SK. Diuretic renal scintigraphy in normal dogs. Vet Radiol Ultrasound 2006; 47(6): 602-608.

Trop J Pharm Res, November 2016; 15(11): 2412 
12. Hecht S, Lane IF, Daniel GB, Orandi F, Sharp DE. Diuretic renal scintigraphy in normal cats. Vet Radiol Ultrasound 2008; 49(6): 589-594.

13. Blaufox M. Procedures of choice in renal nuclear medicine. J Nucl Med 1991; 32: 1301-1309.

14. Nally J, Black J. Captopril renography- pathophysiologic considerations and clinical abservations. Semin Nucl Med 1992; 22(2): 85-97.

15. Dabiri OS, Argani H. Comparison of aspirin renogram and captopril renogram in the diognosis of renovasculor hypertension. J Nucl Med Abstract Book Supplement 2001; 42: 5-7.

16. Hecht S, Lawson SM, Lane IF, Sharp DE, Daniel GB. 99mTc-DTPA diuretic renal scintigraphy in cats with nephroureterolithiasis. J Feline Med Surg 2010; 12(6): 423-430.
17. Imanishi $M$, Yano $M$, Hayashida $K$, Ishida $Y$, Takamiya $M$, Kimura G, Kojima S, Kawano $Y$, Matsushima $Y$, Matsuoka $\mathrm{H}$ et al. Aspirin renography to detect unilateral renovascular hypertension. Kidney Int 1994; 45: 11701176.

18. Kostadinova I, Simeonova A, Delijska B. Comparative assessment of captopril and aspirin administration during dynamic renal scintigraphy in diagnosing renovascular hypertension. Rentgen Radiol 1997; 36(2): 40-43.

19. Maini A, Gambhir S, Singhal M, Kher V. Aspirin renography in the diagnosis of renovascular hypertension: a comparative study with captopril renography. Nucl Med Commun 2000; 21(4): 325-331. 